\title{
Fatiga y accidentabilidad durante la formación en anestesiología: Encuesta online a dos universidades en Chile
}

\author{
Alzola C. ${ }^{1}$, Henríquez M. ${ }^{1}$, Sepúlveda D. ${ }^{1}$, Tartari AM. ${ }^{2}$, Maldonado F. ${ }^{1}$ \\ 1 Hospital Clínico Universidad de Chile, Santiago, Chile. \\ 2 Clínica Santa María, Santiago, Chile.
}

Introducción: Los residentes de anestesiología en formación son sometidos a elevada carga laboral y académica. Esto se asocia a problemas en el ámbito personal y aumento de la tasa de accidentes. Esto aún no ha sido evaluado en Chile. Realizamos una encuesta a residentes de anestesiología de dos universidades de Santiago de Chile con el objetivo de evaluar, de forma piloto, el impacto que tiene esta alta carga en la vida de los estudiantes.

Metodología: Una encuesta anónima fue enviada por correo electrónico a los médicos en proceso de formación en anestesiología. Se obtuvo información sobre horas de trabajo presencial, no presencial. Se solicitó un auto reporte de la ocurrencia de accidente o "casi accidentes" de trayecto hacia o desde su centro de formación. Además, se consultó sobre el uso de medicamentos o sustancias. Finalmente, se realizaron preguntas sobre el impacto subjetivo que tiene la fatiga en sus actividades personales y vida diaria. Las variables fueron expresadas como porcentajes o frecuencias relativas.

Resultados: Se envió la encuesta a 66 residentes, siendo contestada por un $64 \%$ de estos. El $69 \%$ de los encuestados refiere jornadas de 60 a 80 horas semanales de forma presencial. Sumado a esto, la mayoría refiere necesitar entre 6 a 10 horas semanales de dedicación no presencial. El 71\% de los encuestados refiere tener al menos un turno a la semana. Los turnos en su mayoría corresponden a jornadas de 20 a 30 horas. El 12\% de los encuestados refiere el uso de sustancias para conciliar el sueño, mientas que el $66 \%$ requiere su uso para permanecer despierto. Sólo cinco encuestados (12\%) refieren haber tenido un accidente en el trayecto a su hogar debido a estar fatigados, sin embargo, un $50 \%$ refiere haber tenido un evento que catalogan como "casi accidente". Finalmente, al preguntar por el impacto de la fatiga en distintas áreas de la vida personal, el $83 \%$ refiere que ha afectado sus relaciones personales, $90 \%$ su salud física, un $76 \%$ su bienestar psicológico, $83 \%$ su habilidad para realizar trabajo asistencial y un $95 \%$ cree ver afectado su habilidad para realizar trabajo académico.

Conclusiones: Existe una asociación subjetiva, por parte de los residentes de anestesiología, a accidentabilidad e impacto relevante en áreas personales, salud y habilidad para desempeñar su actividad laboral y académica. La formación de especialistas en estas condiciones puede llevar a los residentes a burnout, reduciendo de ese modo la efectividad de la enseñanza.

https://doi.org/10.25237/congresoclasa2019.35 